\title{
Mesolimbic Dopamine Neurons in the Brain Reward Circuit Mediate Susceptibility to Social Defeat and Antidepressant Action
}

\author{
Jun-Li Cao, ${ }^{1,2}$ Herbert E. Covington III, ${ }^{3}$ Allyson K. Friedman, ${ }^{4}$ Matthew B. Wilkinson, ${ }^{3}$ Jessica J. Walsh, ${ }^{4}$ \\ Donald C. Cooper, ${ }^{1}$ Eric J. Nestler, ${ }^{3,4}$ and Ming-Hu Han ${ }^{1,3,4}$ \\ ${ }^{1}$ Department of Psychiatry, University of Texas Southwestern Medical Center, Dallas, Texas 75390-9070, ${ }^{2}$ Jiangsu Province Key Laboratory of \\ Anesthesiology, Xuzhou Medical College, Xuzhou 221002, China, and ${ }^{3}$ Fishberg Department of Neuroscience, and ${ }^{4}$ Department of Pharmacology and \\ Systems Therapeutics, Mount Sinai School of Medicine, New York, New York, 10029-6574
}

We previously reported that the activity of mesolimbic dopamine neurons of the ventral tegmental area (VTA) is a key determinant of behavioral susceptibility vs resilience to chronic social defeat stress. However, this was based solely on ex vivo measurements, and the in vivo firing properties of VTA dopamine neurons in susceptible and resilient mice, as well as the effects of antidepressant treatments, remain completely unknown. Here, we show that chronic $(10 \mathrm{~d})$ social defeat stress significantly increased the in vivo spontaneous firing rates and bursting events in susceptible mice but not in the resilient subgroup. Both the firing rates and bursting events were significantly negatively correlated with social avoidance behavior, a key behavioral abnormality induced by chronic social defeat stress. Moreover, the increased firing rates, bursting events, and avoidance behavior in susceptible mice were completely reversed by chronic ( 2 week), but not acute (single dose), treatments with the antidepressant medication fluoxetine $(20 \mathrm{mg} / \mathrm{kg})$. Chronic social defeat stress increased hyperpolarization-activated cation current $\left(\mathrm{I}_{\mathrm{h}}\right)$ in VTA dopamine neurons, an effect that was also normalized by chronic treatment with fluoxetine. As well, local infusion of $\mathrm{I}_{\mathrm{h}}$ inhibitors ZD7288 $(0.1 \mu \mathrm{g})$ or DK-AH $269(0.6 \mu \mathrm{g})$ into the VTA exerted antidepressant-like behavioral effects. Together, these data suggest that the firing patterns of mesolimbic dopamine neurons in vivo mediate an individual's responses to chronic stress and antidepressant action.

\section{Introduction}

Antidepressants acutely induce a rapid increase in monoamine neurotransmission in the brain, but the mood-elevating effects of these medications in depressed patients, effects that are absent in healthy humans, take several weeks to months to manifest (Oswald et al., 1972; Nestler et al., 2002; Berton and Nestler, 2006). These clinical observations suggest that antidepressants induce gradually developing changes in brain uniquely in affected individuals. In previous studies, we characterized a chronic social defeat stress model of depression, one of the few in which chronic stress-induced molecular and behavioral changes are responsive to chronic, but not acute, antidepressant administration (Berton et al., 2006). Using this model, we demonstrated that the mesolimbic dopamine system, a depression-related neural pathway (Fibiger and Phillips, 1981) composed of dopaminergic (DA) neurons of the ventral tegmental area (VTA) and their projections to the nucleus accumbens, plays an essential role in social

Received June 20, 2010; revised Sept. 23, 2010; accepted 0ct. 6, 2010.

This work was supported by grants from the National Institute of Mental Health (E.J.N.) and National Alliance for Research on Schizophrenia and Depression (M.H.H.).

Correspondence should be addressed to Ming-Hu Han, Department of Pharmacology and Systems Therapeutics, Mount Sinai School of Medicine, New York, NY 10029-6574. E-mail: ming-hu.han@mssm.edu.

D. C. Cooper's present address: Department of Psychology and Neuroscience, Institute for Behavioral Genetics, University of Colorado, Boulder, $\mathrm{C} 080303$.

DOI:10.1523/JNEUROSCI.3177-10.2010

Copyright $\odot 2010$ the authors $\quad 0270-6474 / 10 / 3016453-06 \$ 15.00 / 0$ defeat-induced behavioral abnormalities (Berton et al., 2006), and we inferred that the activity of VTA DA neurons, measured in brain slices ex vivo, is a key determinant of behavioral susceptibility vs resilience to social defeat (Krishnan et al., 2007; Feder et al., 2009). These earlier results were surprising, since they showed increased VTA firing ex vivo, a proreward effect, in susceptible but not resilient mice, raising the question of whether such an increase is relevant to the in vivo situation.

It is well known that VTA DA neurons exhibit two patterns of spontaneous firing activity: a slow-frequency, single-spike firing and a burst firing. The burst-firing mode generates a substantially larger increase of dopamine release than single spiking, and more effectively regulates the activity of neurons in DA target areas, by which VTA DA neurons encode reward-related signals (Grace et al., 2007). However, while burst-firing activity is functionally very important, it is absent in VTA slice preparations (Kitai et al., 1999). In the present study, we used this established depression model to investigate the effects of social defeat on the in vivo firing properties of VTA DA neurons. Furthermore, we studied the effects of acute and chronic fluoxetine, a widely prescribed antidepressant, in this model to test whether these neurons might contribute to antidepressant action.

\section{Materials and Methods}

Animals. Seven-week-old C57BL/6 male mice (Jackson Laboratories) and CD1 retired breeders (Charles River) were used for these studies. All 
experiments were conducted in accordance with guidelines of the Institutional Animal Care and Use Committees at University of Texas Southwestern Medical Center and Mount Sinai School of Medicine.

Chronic social defeat stress. This paradigm was performed exactly as reported (Krishnan et al., 2007). C57BL/6 mice were exposed to a different CD1 aggressor mouse each day for $10 \mathrm{~min}$ over a total of $10 \mathrm{~d}$. On day 11, a social interaction test (Ethovision 3.0 software) identified subgroups of susceptible and resilient mice. This was accomplished by placing mice in an interaction test box, with their movement tracked for 2.5 min in the absence and presence of a caged, unfamiliar target CD1 mouse, respectively. The interaction ratio was calculated as $100 \times$ (interaction time, target present)/(interaction time, target absent). Based on our previous work, an interaction ratio of 100 was set as a cutoff: mice with scores $<100$ were defined as "susceptible" and those with scores $\geq 100$ were defined as "unsusceptible" or resilient.

Fluoxetine treatment. Fluoxetine ( $20 \mathrm{mg} / \mathrm{kg}$; Eli Lily and Company) in PBS was administered through intraperitoneal injection daily at 4:005:00 P.M. for 14-27 d in susceptible and control mice.

In vivo recordings. In vivo extracellular single-cell recordings were performed using published methods (McClung et al., 2005; Mameli-Engvall et al., 2006). Mice were anesthetized with $8 \%$ chloral hydrate $(400 \mathrm{mg} / \mathrm{kg}$, i.p.). Microelectrodes (15-20 M $\Omega$ ) were filled with $2 \mathrm{M} \mathrm{NaCl}$ with $1 \%$ fast green (to mark location of the electrode tip). Coordinates for the VTA were as follows (in mm): anteroposterior (AP), 2.92-3.88; midline (ML), 0.24-0.96; and dorsoventral (DV), 3.5-4.5.

DA cells were identified by anatomical location in the VTA (fast green check) and according to standard physiological criteria (Marinelli and White, 2000; McClung et al., 2005). These neurons exhibited the following: (1) a typical triphasic action potential with a marked negative deflection; (2) a characteristic long duration $(>2.0 \mathrm{~ms}$ ); (3) an action potential width from start to negative trough $\geq 1.1 \mathrm{~ms}$; and (4) a slow firing rate $(<10 \mathrm{~Hz})$ with an irregular single spiking pattern and occasional short, slow bursting activity. Two criteria were used to confirm burst firing: (1) onset was defined by two consecutive spikes within an interval $<80 \mathrm{~ms}$; and (2) termination with an interval $>160 \mathrm{~ms}$.

Electrical signals were amplified and filtered ( $0.3-1 \mathrm{kHz}$ bandpass) by an extracellular preamplifier (Dagan) and monitored audibly through an audio monitor (A.M. Systems). Signals were digitized with an Instru Tech ITC-18 analog-to-digital converter. The data were analyzed using IGOR Pro software (WaveMetrics).

Each DA cell's firing was based on at least 5 min of stable recordings in vivo. Each recording was analyzed with respect to the following parameters: (1) average firing rates; (2) percentage of burst-firing cells (burstfiring cell was defined as at least one burst event in a 5 min recording period, percentage of burst-firing cells $=$ number of burst-firing cells/ number of total recorded cells $\times 100 \%$ ); (3) percentage of spikes within bursts (number of spikes within bursts/total number of spikes $\times 100 \%$ ); and (4) average number of spikes in a burst (total number of spikes in burst/number of burst events).

Whole-cell recordings. VTA brain slices were obtained as described previously (Krishnan et al., 2007). Whole-cell voltage-clamp was used to observe hyperpolarization-activated cation $\left(\mathrm{I}_{\mathrm{h}}\right)$ current in VTA DA neurons. The pipettes $(2-4 \mathrm{M} \Omega$ ) were filled with internal solution containing the following (in $\mathrm{mm}$ ): $115 \mathrm{~K}$-gluconate, $20 \mathrm{KCl}, 1.5 \mathrm{MgCl}_{2}, 10$ phosphocreatine-Tris, $2 \mathrm{Mg}$-ATP, $0.5 \mathrm{Na}_{2}$-GTP, and 10 HEPES. DA neurons were identified by the presence of an $\mathrm{I}_{h}$ (Saal et al., 2003). $\mathrm{I}_{\mathrm{h}}$ currents were elicited by repetitive $800 \mathrm{~ms}$ pulses with $10 \mathrm{mV}$ increments from a holding potential of -60 to $-140 \mathrm{mV}$ in the presence of kynurenic acid $(1 \mathrm{mmol} / \mathrm{L}$ ) and $100 \mu \mathrm{mol} / \mathrm{L}$ picrotoxin. A patch-clamp amplifier (Axon 700B) was used for voltage-clamp recording. Signals were digitized with an Instru Tech ITC-18 analog-to-digital converter. Data were analyzed using IGOR Pro software (WaveMetrics).

VTA micro-infusion of $I_{h}$ inhibitors. Chronically stressed and nonstressed mice received a VTA infusion of the $\mathrm{I}_{\mathrm{h}}$ inhibitors ZD7288 or DK-AH 269, or PBS as control. Specifically, $48 \mathrm{~h}$ after their last defeat stress (or control condition), mice were placed under a combination of ketamine $(100 \mathrm{mg} / \mathrm{kg})$ and xylazine $(10 \mathrm{mg} / \mathrm{kg})$ anesthesia before bilateral implantation of 26 gauge guide cannulae fitted with obturators (Plastics One) that were secured to the skull after being positioned $1 \mathrm{~mm}$ directly above the VTA (AP, - 3.2; ML, 0.4; DV, - $3.6 \mathrm{~mm}$ ) (supplemental Fig. S1, available at www.jneurosci.org as supplemental material). After 6-8 d of postoperative recovery, simultaneous bilateral microinjections of ZD7288 $(0.1 \mu \mathrm{g})$, DK-AH $269(0.6 \mu \mathrm{g})$, or PBS were delivered through an injector cannula in a total volume $0.4 \mu \mathrm{l} /$ side at a continuous rate of $0.1 \mu \mathrm{l} / \mathrm{min}$ under the control of a micro-infusion pump (Harvard Apparatus). Concentrations of ZD7288 and DK-AH 269 were selected based on earlier in vivo studies (Chevaleyre and Castillo, 2002; Kocsis and $\mathrm{Li}, 2004)$. Injector cannulae were removed $2 \mathrm{~min}$ after the stopping of each infusion, and mice remained undisturbed in their home cages for an additional 3 min (ZD7288) or $60 \mathrm{~min}$ (DK-AH 269) before testing for social interaction behavior.

Statistics. Data are expressed as mean \pm SEM. One-way ANOVAs followed by a Newman-Keuls post hoc test were used to compare three or more groups in behavioral and in vivo recording data. $\chi^{2}$ tests were used to analyze the change of percentage of bursting cells. Two-way ANOVA was performed when analyzing $\mathrm{I}_{\mathrm{h}}$ currents and behavioral data for infusion of ZD7288 or DK-AH 269. $p<0.05$ was considered statistically significant. GraphPad Prism 5 was used for all statistical analyses.

\section{Results}

Mice subjected to chronic social defeat were segregated into susceptible and resilient subpopulations based on their social avoidance, which correlates with several other behavioral abnormalities (Krishnan et al., 2007). Sixty to 70 percent of mice subjected to this paradigm fell into the susceptible subgroup in this study. Susceptible mice spent significantly less time interacting with other mice compared with controls, a phenomenon absent in resilient mice (Fig. $1 A, B)\left(F_{(2,38)}=22.03, p<0.0001\right.$ ) (supplemental Fig. S2, available at www.jneurosci.org as supplemental material). We then obtained extracellular single-unit recordings from 195 putative VTA DA neurons in anesthetized control, susceptible, and resilient mice. Consistent with previous ex vivo findings from brain slices (Krishnan et al., 2007), chronic social defeat induced a $43.8 \%$ increase in spontaneous firing rates in susceptible mice, with no effect seen in resilient mice (Fig. $1 C, D)\left(F_{(2,192)}=12.54, p<0.0001\right)$. Moreover, there was a significant inverse correlation between the average VTA firing rate for each animal and its social interaction time (Fig. $1 E)(n=35$, $p<0.05$ ), directly relating increased VTA firing in vivo with the deleterious effects of chronic stress.

Importantly, we further found that the firing patterns of VTA DA neurons were dramatically altered by chronic social defeat stress; 43.1\% (28/65) of VTA DA neurons recorded from control mice showed at least one burst-firing event in a 5 min recording period. This percentage of bursting cells increased to $68.0 \%$ (49/ $72)$ in susceptible mice (Fig. $1 F)\left(\chi^{2}=13.00, p<0.01\right)$, while it was not changed in the resilient subgroup $(39.7 \%, 23 / 58)$. The percentage of spikes within bursts, and the number of spikes in a burst, were dramatically increased in susceptible mice, with no significant increase observed in resilient mice (Fig. $1 H, F_{(2,97)}=$ $11.50, p<0.001$; Fig. $\left.1 J, F_{(2,97)}=5.68, p<0.01\right)$. Furthermore, the average change in bursting events for each animal also inversely correlated with its social interaction time (Fig. 1G, $I, K$ ) $(n=35, p<0.05)$. Consistently, firing rates were significantly correlated with the percentage of spikes within bursts for each group, suggesting that the increased firing rates were associated with the increase of bursting events (Fig. $1 L)(n=35$ per group, $p<0.05)$. These findings demonstrate that chronic social defeat induces in vivo maladaptations in the overall firing rate and phasic firing patterns of VTA DA neurons uniquely in susceptible animals, suggesting that such changes play an important role in mediating the deleterious effects of social defeat.

We have shown previously that avoidance behavior induced by chronic social defeat can be normalized by chronic but not 
A

Behavioral test

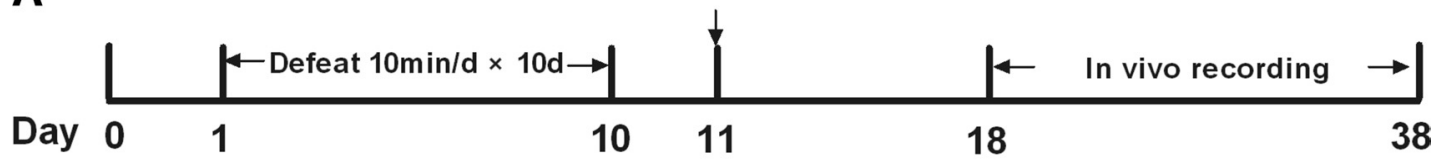

B

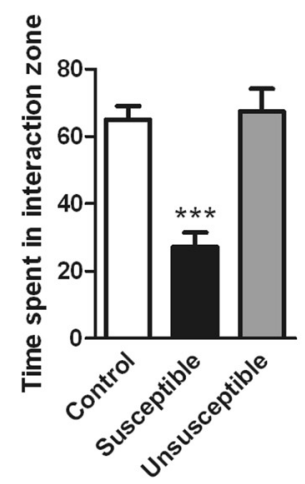

E
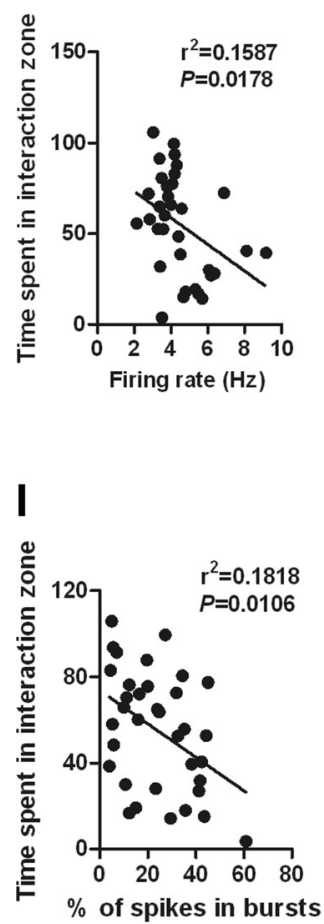

C

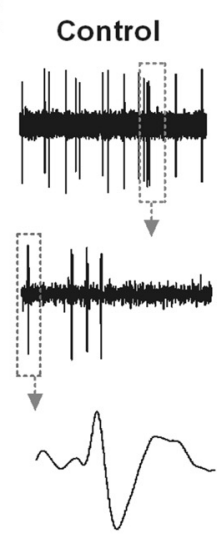

F
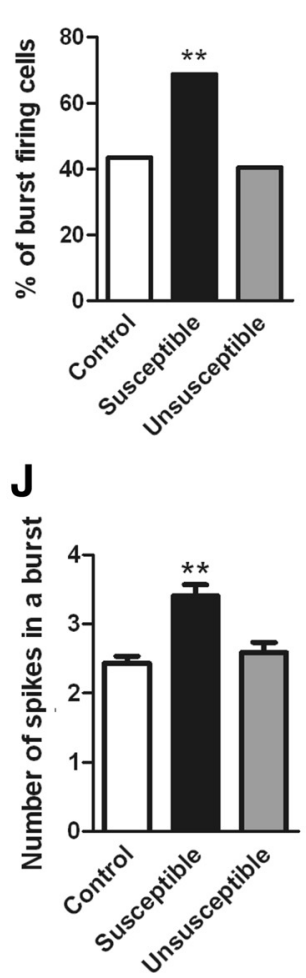

Susceptible

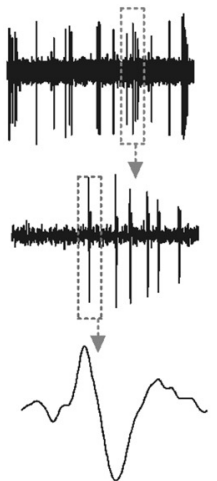

G

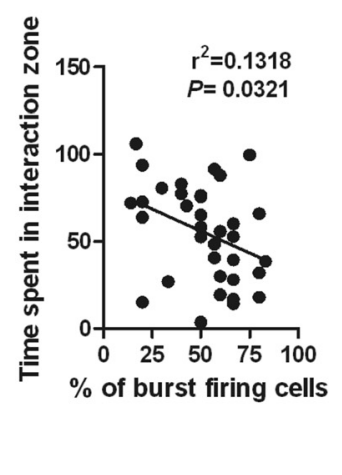

K

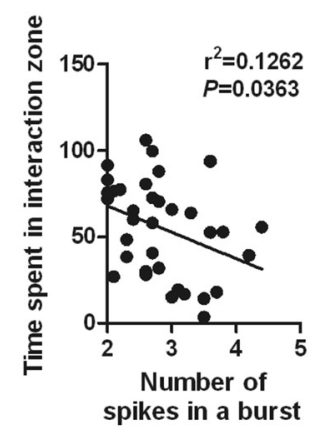

D
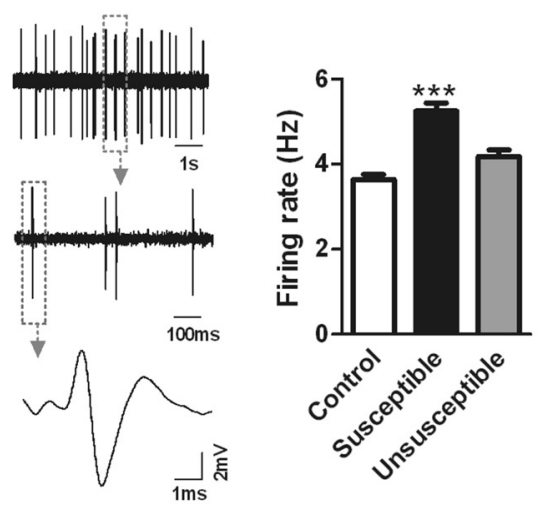

H

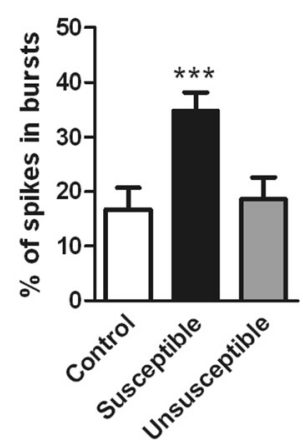

L

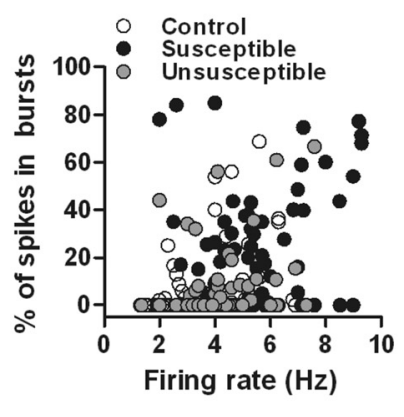

Figure 1. Chronic social defeat stress increases the firing rates and bursting events in VTA DA neurons in susceptible, not resilient (unsusceptible), mice. A, Timeline of chronic social defeat, behavioral testing, and in vivo recording protocols. $\boldsymbol{B}$, The time spent in the interaction zone during a social interaction test ${ }^{* * *} p<0.0001$ vs control or unsusceptible; $8-20$ mice/group). C, Sample traces, bursting events, and spikes for in vivo recordings from VTA DA neurons from control, susceptible, and unsusceptible mice. $\boldsymbol{D}$, Overall VTA firing rates in control, susceptible, and unsusceptible mice $(* * *)<0.0001$ vs control or unsusceptible mice, $n=58-72$ cells, 15 mice/group). $\boldsymbol{E}$, Average VTA firing rate for each mouse is significantly negatively correlated with the time spent in interaction zone measured on day 11 ( $p<0.05, n=35$ mice). $\boldsymbol{F}, \boldsymbol{H}, \boldsymbol{J}$, Burst-firing events of VTA DA neurons, including percentage of burst-firing cells, percentage of spikes in bursts, and number of spikes in a burst, were increased in susceptible, not unsusceptible, mice ${ }^{* * *} p<0.01,{ }^{* * *} p<0.001$ vs control or unsusceptible mice; $n=23-49$ cells, $8-15$ mice/group). $\mathbf{G}, \mathbf{I}, \boldsymbol{K}$, The average changes of these bursting events for each animal also inversely correlated with its social interaction time $(p<0.05 ; n=$ 35 mice). L, Scatter plot of the bursting activity and firing rates of all neurons recorded from control, susceptible, and unsusceptible mice. Note the large number of VTA DA neurons in susceptible mice with high firing rate and more bursting activity. Firing rates are significantly positively correlated with percentage of spikes in bursts in all threegroups, suggesting the increased firing rates were associated with the increase of bursting events (control: $r^{2}=0.127, n=65$ cells $/ 15$ mice, $p<0.001$; susceptible: $r^{2}=0.0952, n=72$ cells $/ 12$ mice, $p<0.001$; unsusceptible: $r^{2}=0.0758, n=58$ cells/8 mice, $p<0.05$ ).

acute administration of antidepressants (Berton et al., 2006). Therefore, we asked whether antidepressant treatment reverses the defeat-induced firing maladaptations of VTA DA neurons in susceptible mice. We subjected mice to chronic social defeat, identified susceptible mice with a social interaction test on day 11 , and then treated susceptible and control mice with fluoxetine $(20 \mathrm{mg} / \mathrm{kg}$ ) or vehicle for $\sim 20 \mathrm{~d}$ (Fig. $2 A$ ). Separate groups of animals received vehicle injections for $19 \mathrm{~d}$ and a single injection 


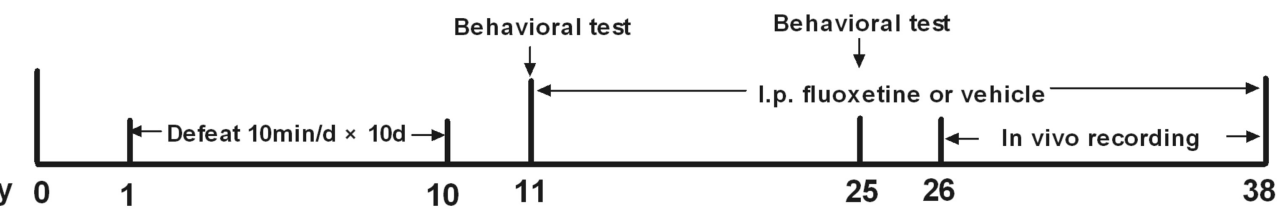

B

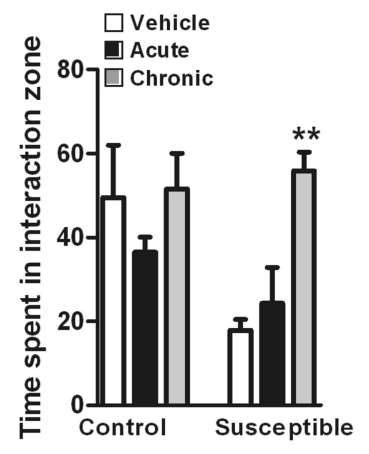

F

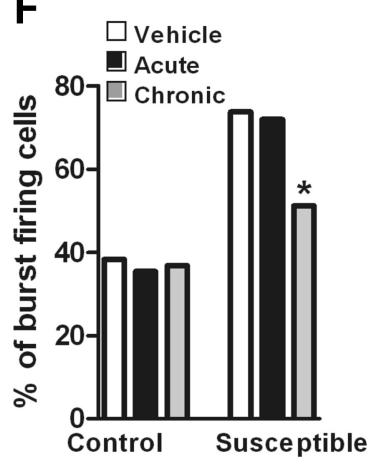

C

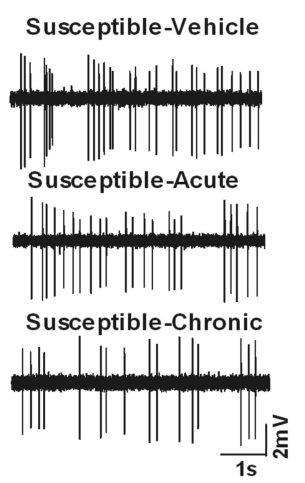

G

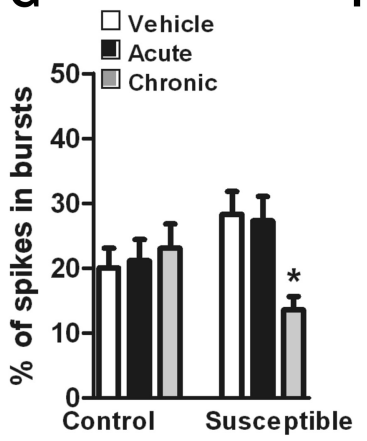

D

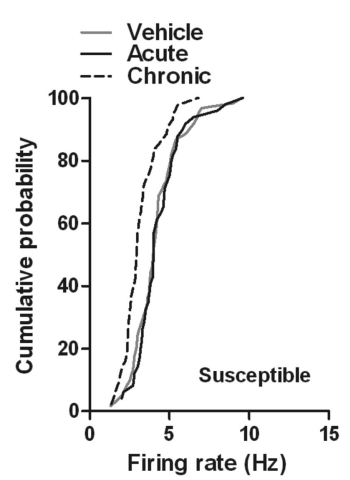

H

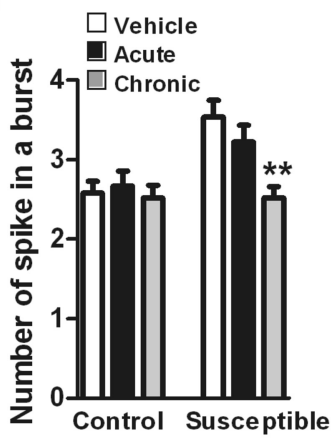

E

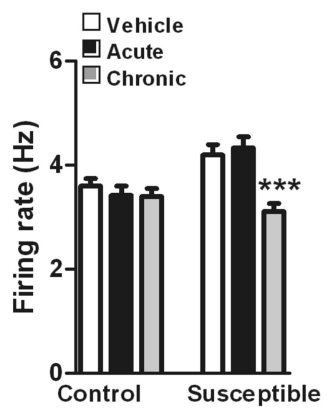

I

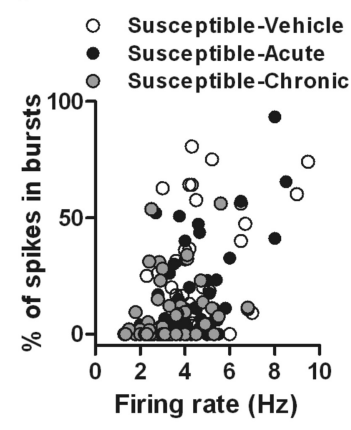

Figure 2. Chronic treatment with fluoxetine normalizes stress-induced maladaptations of VTA DA neurons in susceptible mice. $A$, Timeline of chronic social defeat, behavioral testing, treatment with fluoxetine, and in vivo recording protocols. $B$, Chronic, not acute, administration of fluoxetine normalized defeat-induced avoidance behavior in susceptible mice $\left({ }^{* *} p<0.01 \mathrm{vs}\right.$ susceptiblevehicle mice, 5-7 mice/group). C, Sample traces for in vivo recordings from VTA DA neurons from susceptible mice with acute or chronic treatment with vehicle or fluoxetine. D, Cumulative probability distribution plots of VTA firing rates in susceptible mice after acute or chronic treatment with vehicle or fluoxetine. $E$, Acute or chronic treatment with vehicle or fluoxetine did not change the firing rates of VTA DA neurons in control mice ( $p>0.5, n=46-48$ cells, 5 mice/group), and chronic, not acute, administration of fluoxetine normalized the increased firing rates of VTA DA neurons in susceptible mice ${ }^{* * *} p<0.001$ vs susceptible-vehicle or susceptible-acute mice; $n=43-64$ cells, $5-6$ mice/group). $\boldsymbol{F}$ - $\boldsymbol{H}$, Acute or chronic treatment with vehicle or fluoxetine did not change burst events of VTA DA neurons in control mice ( $p>0.5, n=20-21$ cells, 5 mice/group), however, chronic, not acute, administration of fluoxetine reversed the increased burst events of VTA DA neurons in susceptible mice ( ${ }^{*} p<0.05,{ }^{* *} p<0.01$ vs susceptible-vehicle or susceptible-acute mice, $n=22-45$ cells, $5-6$ mice/group). I, Scatter plot of percentage of spikes in bursts and firing rates of all neurons recorded from susceptible-vehicle $(n=61)$, susceptible-acute $(n=50)$, and susceptible-chronic $(n=43)$ mice. Note the small number of VTA DA neurons with high firing rates and more bursting activity in susceptible mice after chronic treatment with fluoxetine.

of fluoxetine on day 20 . We first replicated published findings at the behavioral level, namely, that chronic, but not acute, fluoxetine administration fully reversed social defeat-induced avoidance behavior (Fig. $2 B, F_{(2,15)}=14.23, p<0.01$ ). We then performed in vivo recordings of VTA DA neurons in control and susceptible mice the day after this social interaction test. We found that acute or chronic treatment with fluoxetine did not change either the overall firing rates (Fig. $2 C, E)\left(F_{(2,138)}=0.45\right.$, $p>0.05$ ) or bursting events (Fig. $2 F-H$ ) (percentage of burstfiring cells: $\chi^{2}=0.09, p>0.05$; percentage of spikes within bursts: $F_{(2,49)}=0.14, p>0.05$; average number of spikes in a burst: $\left.F_{(2,49)}=0.20, p>0.05\right)$ in VTA DA neurons of control mice. However, chronic fluoxetine treatment fully normalized the defeat-induced increased firing rate and burst events of VTA DA neurons in susceptible mice, while acute fluoxetine had no effect on these parameters. Chronic fluoxetine induced a $23.8 \%$ decrease in overall firing rates (Fig. $2 C-E)\left(F_{(2,151)}=6.42, p<\right.$ 0.0001 ) and decreased the percentage of bursting cells from 73.8 to $51.1 \%$ (Fig. $2 F)\left(\chi^{2}=6.70, p<0.05\right)$, the percentage of spikes in bursts from 28.3 to $13.6 \%$ (Fig. $2 G)\left(F_{(2,100)}=3.68, p<0.05\right)$, and the number of spikes in a burst from 3.52 to 2.52 spikes (Fig. $2 H)\left(F_{(2,100)}=4.95, p<0.01\right)$. There were a small number of VTA DA neurons with high firing rates and more bursting activity in susceptible mice after chronic fluoxetine treatment (Fig. $2 I$ ). Together, these results suggest that fluoxetine's reversal of these in vivo firing properties of VTA DA neurons are involved in antidepressant action in the social defeat model.

Next, we studied the possible ionic mechanisms that underlie the social defeat-induced changes in VTA firing properties. It is well known that $\mathrm{I}_{\mathrm{h}}$ channels, expressed in VTA DA neurons, can intrinsically regulate its pacemaker activity and the transition from single spike to burst mode (Neuhoff et al., 2002; ArencibiaAlbite et al., 2007; Inyushin et al., 2010). Recent studies have shown that $\mathrm{I}_{\mathrm{h}}$ current is involved in adaptations of VTA DA neurons to corticotrophin-releasing factor (CRF) (Wanat et al., 2008). We, therefore, speculated that an increase in excitatory $I_{h}$ 
A

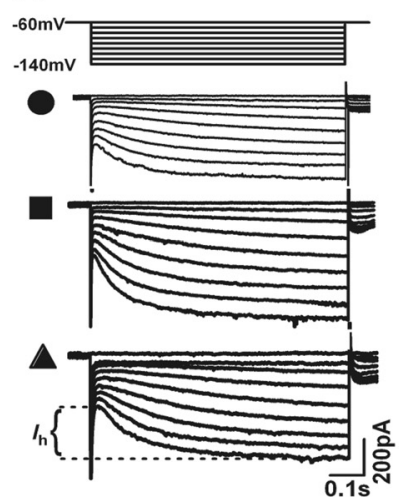

B

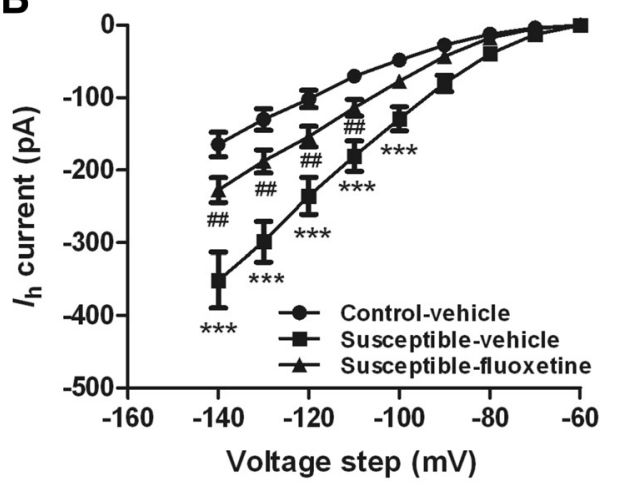

C

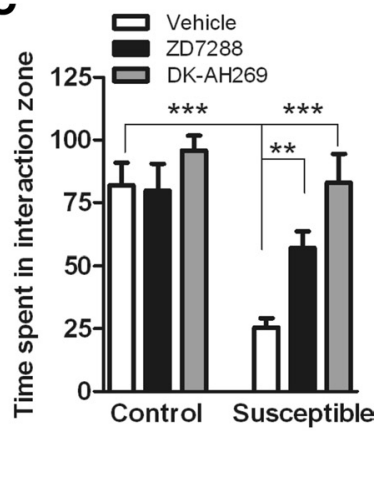

Figure 3. $I_{h}$ channels in VTA DA neurons were involved in defeat-induced avoidance behavior and action of fluoxetine. $\boldsymbol{A}, I_{\mathrm{h}}$ currents were elicited by repetitive 800 ms pulses with 10 mV increments from a holding potential of -60 to $-140 \mathrm{mV}$. Sample traces recorded from control-vehicle, susceptible-vehicle, and susceptible-fluoxetine mice. $\boldsymbol{B}$, Chronic social defeat increased $\mathrm{I}_{\mathrm{h}}$ currents in VTA DA neurons, which was almost completely reversed by chronic treatment with fluoxetine $\left({ }^{* * *} p<0.0001\right.$ vs control-vehicle mice, ${ }^{\# \#} p<0.01$ vs susceptible-fluoxetine mice, $n=$ $35-66$ cells, $10-12$ mice/group). C, Infusion of $\mathrm{I}_{\mathrm{h}}$ channel inhibitor ZD7288 or DK-AH 269 into VTA significantly reversed the stress-induced social avoidance ${ }^{* *} p<0.01,{ }^{* * *} p<0.001 ; n=6-11$ mice).

current may contribute to the changes in firing rate and bursting pattern of VTA DA neurons in susceptible mice. To test this possibility, whole-cell voltage-clamp recordings were obtained to measure $\mathrm{I}_{\mathrm{h}}$ current from DA neurons in VTA slice preparations of control and susceptible mice with or without chronic treatment with fluoxetine. VTA DA neurons were identified electrophysiologically by the presence of a large $I_{h}$ current (Saal et al., 2003). We found that chronic social defeat dramatically increased $I_{h}$ current in VTA DA neurons in susceptible mice (Fig. $3 A, B$ ) $\left(F_{(2,146)}=6.83, p<0.0001\right)$, suggesting that $\mathrm{I}_{\mathrm{h}}$, as an intrinsic factor, contributes to social defeat-induced increases in the electrical excitability of VTA DA neurons. To test the role of $\mathrm{I}_{\mathrm{h}}$ channels in mediating the effects of social defeat, we infused the $I_{h}$ channel inhibitors ZD7288 or DK-AH 269 into the VTA and examined their effects on the deleterious behavioral consequences of chronic social defeat stress. Both ZD7288 and DK-AH 269 significantly reversed stress-induced social avoidance without altering general locomotor activity (Fig. $3 C)\left(F_{(2,49)}=9.67\right.$, $p<0.001$; no interaction, $p>0.05)$. Consistent with this finding, the defeat-induced increase in $\mathrm{I}_{\mathrm{h}}$ current in VTA DA neurons was largely reversed by chronic fluoxetine treatment (Fig. 3A,B) $\left(F_{(2,146)}=6.83, p<0.01\right)$.

\section{Discussion}

We show here that chronic social defeat induces maladaptations in the in vivo firing properties of VTA DA neurons, and in an associated ionic mechanism, that are tightly correlated with stress-induced behavioral abnormalities. Moreover, we show that chronic (not acute) treatment with fluoxetine normalizes these defeat-induced maladaptations at the behavioral and electrophysiological levels.

There is increasing interest in the involvement of the mesolimbic dopamine system in depression given its role in hedonia and motivation (Nestler and Carlezon, 2006). However, functional changes in VTA DA neurons that mediate depression-like behaviors and antidepressant action remain controversial. Some studies found that a deficiency in dopaminergic function may contribute to the pathogenesis of depression such as in Flinders Sensitive Line rats, a genetic model of depression (Yadid and Friedman, 2008). The deficiency can be restored to normal levels by chronic antidepressant treatment (Friedman et al., 2008). In contrast, other studies found increased activity of VTA DA neu- rons in stress-induced depression models such as after chronic restraint or social defeat (Anstrom and Woodward, 2005; Berton et al., 2006; Krishnan et al., 2007). Here, we show that the in vivo firing rate and bursting properties of VTA DA neurons are dramatically increased in susceptible mice but not in resilient mice, consistent with our previous findings in brain slices (Krishnan et al., 2007). Recently, deep brain stimulation (DBS) of lateral habenula ( $\mathrm{LHa}$ ) was found to induce remission in a treatmentresistant depressed patient (Sartorius et al., 2010). There is consistent evidence showing that stimulation of LHa inhibits the activity of VTA DA neurons (Christoph et al., 1986; Ji and Shepard, 2007). Hence, it is possible that the clinical efficacy of LHa DBS is mediated via inhibition of VTA DA neuron activity, consistent with our social defeat model.

We demonstrate that the increased firing of VTA DA neurons seen after chronic social defeat is mediated, at least partly, via increased $\mathrm{I}_{\mathrm{h}}$ current. $\mathrm{I}_{\mathrm{h}}$ not only regulates VTA DA neuron tonic firing, but also regulates the transition between single spike and burst firing (Arencibia-Albite et al., 2007; Inyushin et al., 2010). Interestingly, enhanced $\mathrm{I}_{\mathrm{h}}$ current is observed not only in susceptible mice, but in resilient mice as well (166\% increase over nondefeated controls, $p<0.01$ ). This finding suggests that resilience is associated with additional adaptations that compensate for the increase in $\mathrm{I}_{\mathrm{h}}$. Indeed, we have shown previously that resilience uniquely is associated with induction of several $\mathrm{K}^{+}$channel subunits (Krishnan et al., 2007), which could normalize VTA firing rates despite the enhanced $\mathrm{I}_{\mathrm{h}}$. Likewise, we show here that chronic fluoxetine treatment normalizes the increased firing rate of VTA DA neurons in susceptible mice, as well as the defeat-induced increase in $\mathrm{I}_{\mathrm{h}}$ current. Many neurotransmitters such as CRF and glutamate are known to regulate $\mathrm{I}_{\mathrm{h}}$ currents (Wanat et al., 2008). Further work is needed to understand the detailed mechanisms by which fluoxetine, which acts initially to enhance serotoninergic neurotransmission, regulates $\mathrm{I}_{\mathrm{h}}$ current in VTA DA neurons after chronic administration.

Firing adaptations of VTA DA neurons have also been observed in mouse models of other psychiatric disorders such as drug addiction and bipolar disorder (McClung et al., 2005; Roybal et al., 2007), suggesting that a range of stress-associated psychiatric disorders may share some common neural circuits and even cellular and ionic mechanisms. Manipulation of VTA DA 
neuronal excitability with various methods, such as pharmacological tools, optogenetic approaches, or deep brain stimulation, could be an effective treatment strategy for these disorders.

\section{References}

Anstrom KK, Woodward DJ (2005) Restraint increases depaminergic bursting firing in awake rats. Neuropsychopharmacology 30:1832-1840.

Arencibia-Albite F, Paladini C, Williams JT, Jiménez-Rivera CA (2007) Noradrenergic modulation of the hyperpolarization-activated cation current $\left(I_{\mathrm{h}}\right)$ in dopamine neurons of the ventral tegmental area. Neuroscience 149:303-314.

Berton O, Nestler EJ (2006) New approaches to antidepressant drug discovery: beyond monoamines. Nat Rev Neurosci 7:137-151.

Berton O, McClung CA, Dileone RJ, Krishnan V, Renthal W, Russo SJ, Graham D, Tsankova NM, Bolanos CA, Rios M, Monteggia LM, Self DW, Nestler EJ (2006) Essential role of BDNF in the mesolimbic dopamine pathway in social defeat stress. Science 311:864-868.

Chevaleyre V, Castillo PE (2002) Assessing the role of $\mathrm{I}_{\mathrm{h}}$ channels in synaptic transmission and mossy fiber LTP. Proc Natl Acad Sci U S A 99:9538-9543.

Christoph GR, Leonzio RJ, Wilcox KS (1986) Stimulation of the lateral habenula inhibits dopamine-containing neurons in the substantia nigra and ventral tegmental area of the rat. J Neurosci 6:613-619.

Feder A, Nestler EJ, Charney DS (2009) Psychobiology and molecular genetics of resilience. Nat Rev Neurosci 10:446-457.

Fibiger HC, Phillips AG (1981) Increased intracranial self-stimulation in rats after long-term administration of desipramine. Science 214:683-685.

Friedman A, Friedman Y, Dremencov E, Yadid G (2008) VTA dopamine neuron bursting is altered in an animal model of depression and corrected by desipramine. J Mol Neurosci 34:201-209.

Grace AA, Floresco SB, Goto Y, Lodge DJ (2007) Regulation of firing of dopaminergic neurons and control of goal-directed behaviors. Trends Neurosci 30:220-227.

Inyushin MU, Arencibia-Albite F, Vázquez-Torres R, Vélez-Hernández ME, Jiménez-Rivera CA (2010) Alpha-2 noradrenergic receptor activation inhibits the hyperpolarization-activated cation current $\left(\mathrm{I}_{\mathrm{h}}\right)$ in neurons of the ventral tegmental area. Neuroscience 167:287-297.

Ji H, Shepard PD (2007) Lateral habenula stimulation inhibits rat midbrain dopamine neurons through a $\mathrm{GABA}_{\mathrm{A}}$ receptor-mediated mechanism. J Neurosci 27:6923-6930.

Kitai ST, Shepard PD, Callaway JC, Scroggs R (1999) Afferent modulation of dopamine neuron firing patterns. Curr Opin Neurobiol 9:690-697.

Kocsis B, Li S (2004) In vivo contribution of h-channels in the septal pacemaker to theta rhythm generation. Eur J Neurosci 20:2149-2158.
Krishnan V, Han MH, Graham DL, Berton O, Renthal W, Russo SJ, Laplant Q, Graham A, Lutter M, Lagace DC, Ghose S, Reister R, Tannous P, Green TA, Neve RL, Chakravarty S, Kumar A, Eisch AJ, Self DW, Lee FS, Tamminga CA, Cooper DC, Gershenfeld HK, Nestler EJ (2007) Molecular adaptations underlying susceptibility and resistance to social defeat in brain reward regions. Cell 131:391-404.

Mameli-Engvall M, Evrard A, Pons S, Maskos U, Svensson TH, Changeux JP, Faure P (2006) Hierarchical control of dopamine neuron-firing patterns by nicotinic receptors. Neuron 50:911-921.

Marinelli M, White FJ (2000) Enhanced vulnerability to cocaine selfadministration is associated with elevated impulse activity of midbrain dopamine neurons. J Neurosci 20:8876-8885.

McClung CA, Sidiropoulou K, Vitaterna M, Takahashi JS, White FJ, Cooper DC, Nestler EJ (2005) Regulation of dopaminergic transmission and cocaine reward by the Clock gene. Proc Natl Acad Sci U S A 102:9377-9381.

Nestler EJ, Carlezon WA Jr (2006) The mesolimbic dopamine reward circuit in depression. Biol Psychiatry 59:1151-1159.

Nestler EJ, Barrot M, DiLeone RJ, Eisch AJ, Gold SJ, Monteggia LM (2002) Neurobiology of depression. Neuron 34:13-25.

Neuhoff H, Neu A, Liss B, Roeper J (2002) I(h) channels contribute to the different functional properties of identified dopaminergic subpopulations in the midbrain. J Neurosci 22:1290-1302.

Oswald I, Brezinova V, Dunleavy DL (1972) On the slowness of action of tricyclic antidepressant drugs. Br J Psychiatry 120:673-677.

Roybal K, Theobold D, Graham A, DiNieri JA, Russo SJ, Krishnan V, Chakravarty S, Peevey J, Oehrlein N, Birnbaum S, Vitaterna MH, Orsulak P, Takahashi JS, Nestler EJ, Carlezon WA Jr, McClung CA (2007) Manialike behavior induced by disruption of CLOCK. Proc Natl Acad Sci U S A 104:6406-6411.

Saal D, Dong Y, Bonci A, Malenka RC (2003) Drugs of abuse and stress trigger a common synaptic adaptation in dopamine neurons. Neuron 37:577-582.

Sartorius A, Kiening KL, Kirsch P, von Gall CC, Haberkorn U, Unterberg AW, Henn FA, Meyer-Lindenberg A (2010) Remission of major depression under deep brain stimulation of the lateral habenula in a therapyrefractory patient. Biol Psychiatry 67:e9-e11.

Wanat MJ, Hopf FW, Stuber GD, Phillips PE, Bonci A (2008) Corticotropin-releasing factor increases mouse ventral tegmental area dopamine neuron firing through a protein kinase C-dependent enhancement of $\mathrm{I}_{\mathrm{h}}$. J Physiol 586:2157-2170.

Yadid G, Friedman A (2008) Dynamics of the dopaminergic system as a key component to the understanding of depression. Prog Brain Res 172:265286. 